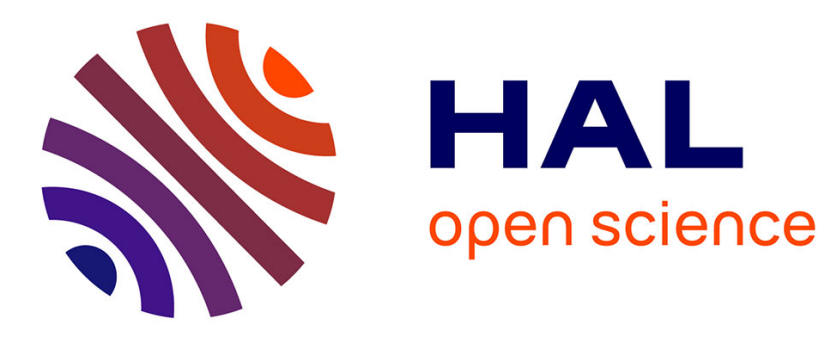

\title{
On the secondary electron emission phenomenon when originating from very thin layers
}

Kremena Makasheva, M. Belhaj, G. Teyssedre, Charles Rigoudy, S. Dadouch, Laurent Boudou

\section{- To cite this version:}

Kremena Makasheva, M. Belhaj, G. Teyssedre, Charles Rigoudy, S. Dadouch, et al.. On the secondary electron emission phenomenon when originating from very thin layers. 2017 IEEE 17th International Conference on Nanotechnology (IEEE-NANO), Jul 2017, Pittsburgh, United States. pp.515-516, 10.1109/NANO.2017.8117275 . hal-02324440

\section{HAL Id: hal-02324440 \\ https://hal.science/hal-02324440}

Submitted on 1 Nov 2019

HAL is a multi-disciplinary open access archive for the deposit and dissemination of scientific research documents, whether they are published or not. The documents may come from teaching and research institutions in France or abroad, or from public or private research centers.
L'archive ouverte pluridisciplinaire HAL, est destinée au dépôt et à la diffusion de documents scientifiques de niveau recherche, publiés ou non, émanant des établissements d'enseignement et de recherche français ou étrangers, des laboratoires publics ou privés. 


\title{
On the secondary electron emission phenomenon when originating from very thin layers*
}

\author{
K. Makasheva, Member, IEEE, M. Belhaj, G. Teyssedre, Member, IEEE, \\ C. Rigoudy, S. Dadouch and L. Boudou
}

\begin{abstract}
The secondary electron emission phenomenon lays down the principle of operation of many physical devices and processes. Although it is fairly well described in the case of irradiation of metals there is still lack of information on the secondary electron emission when originating from dielectrics. In this work we report on the secondary electron emission resulting from very thin layers. It is found that for dielectric $\mathrm{SiO}_{2}$ layers of less than $100 \mathrm{~nm}$ of thickness a departure from the general behaviour occurs for incident primary electrons with energy of around $1 \mathrm{keV}$. The departure in the electron emission yield heavily depends on the layer thickness. The case of nanostructured layers - dielectric matrices containing metal nanoparticles is also considered in the study.
\end{abstract}

\section{INTRODUCTION}

Secondary electron emission is a process of release of electrons from materials. It results from the energy transfer of impinging energetic particles (electrons, ions, photons) to the material surface. This physical phenomenon is largely involved in scanning electron microscopy (SEM) [1], plasma physics [2], space applications [3, 4], particle accelerator [5], etc. Given the large number of devices using secondary electron emission for their operation a lot of effort was made during the last century to determine the electron emission yield (EEY) from different materials, conducting and/or insulating ones [6]. The secondary electron emission is a complex phenomenon that depends on many parameters related to the primary particles (electrons, ions, their energy, incident angle distribution, etc.) or to the nature of the studied material, especially when dealing with insulators due to the charging effect for low energy primary electrons $[6,7]$. Without loss of generality we limit our study to EEY generated by electron impact.

This work represents a new insight in the secondary electron emission from very thin dielectric layers and opens the discussion on nanostructured layers with metallic nanoparticles embedded in dielectric matrices. The study of nanostructured layers aims to account for the gradually increased conductivity of the layer up to a conductive one. To prevent from target charging and consequently to determine the real secondary electron emission yield a short pulse irradiation by primary electrons (PE) was applied.

*Research supported by the program IDEX Actions Thématiques Stratégiques - ATS 2015 of the Université de Toulouse under project SEPHIR (2016-066-CIF-D-DRVD)

K. Makasheva, G. Teyssedre, C. Rigoudy and L. Boudou are with LAPLACE laboratory, Université de Toulouse; CNRS, UPS, INPT; 118 route de Narbonne, F-31062 Toulouse, France (e-mail: kremena.makasheva@laplace.univ-tlse.fr);

M. Belhaj, C. Rigoudy and S. Dadouch are with ONERA-The French Aerospace Lab, Toulouse, France (e-mail: Mohamed.Belhaj@onera.fr).

\section{EXPERIMENTAL PART}

\section{A. Samples elaboration}

Thin silica $\left(\mathrm{SiO}_{2}\right)$ layers, $100 \mathrm{~nm}$-thick, were thermally grown on $\mathrm{Si}$-substrates at $1100^{\circ} \mathrm{C}$ under slightly oxidizing atmosphere using a $\mathrm{N}_{2}-\mathrm{O}_{2}$ gas mixture containing $1.0 \%$ of $\mathrm{O}_{2}$. The targeted thicknesses were obtained after chemical etching of the $\mathrm{SiO}_{2}$ layers using hydrofluoric acid (HF). The samples were then abundantly rinsed with deionized water.

A single layer of silver nanoparticles (AgNPs) was deposited on the surface of $\mathrm{SiO}_{2}$ layer in the plasma of axially-asymmetric capacitively-coupled RF discharge. The discharge powered electrode (smaller electrode) was $\mathrm{Ag}$ made target to bear the silver sputtering. The plasma was maintained in pure argon at low pressure $(p=5.4 \mathrm{~Pa})$ with $\mathrm{RF}$ power of $\mathrm{P}=80 \mathrm{~W}\left(\mathrm{~V}_{\mathrm{dc}}=-1000 \mathrm{~V}\right)$. The sputtering time was fixed to $5 \mathrm{~s}$. More details about the plasma process are given elsewhere [8].

\section{B. Characterization methods}

The thicknesses of $\mathrm{SiO}_{2}$ layers were determined by spectroscopic ellipsometry using a SOPRA GES-5 ellipsometer in the range $250-850 \mathrm{~nm}$. The recorded spectra were modeled with Bruggeman's model to extract the $\mathrm{SiO}_{2}$ layer thicknesses. The monolayer of AgNPs was observed by SEM. The size and density of AgNPs were obtained after image processing.

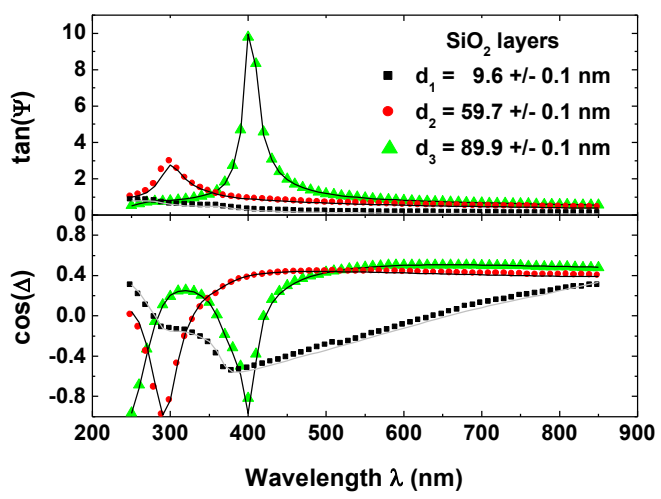

Fig. 1. Recorded ellipsometric spectra (dots) and the simulated spectra (lines) for the studied $\mathrm{SiO}_{2}$ layers

The EEY, encompassing backscattered and SE emissions, was studied in the low energy range, from few $\mathrm{eV}$ up to $2000 \mathrm{eV}$. The measurements were performed under high vacuum $\left(5 \times 10^{-7} \mathrm{~Pa}\right)$. The sample surface was monitored by Auger electron spectroscopy to account for impurities. All experiments were performed with very low contamination 
level. The experimental arrangement and the applied procedure are described elsewhere [9].

\section{RESULTS AND DISCUSSION}

The recorded spectroscopic ellipsometric spectra, alongside with the simulated spectra, are presented in Fig. 1 for the three $\mathrm{SiO}_{2}$ layers. The obtained layer thicknesses are of 9.6, 59.7 and $89.9 \mathrm{~nm}$. Keeping the thickness of the silica layers less than $100 \mathrm{~nm}$ allows for study of the SE features in correlation to PE penetration depth and of the cascade of events following the energy deposition.

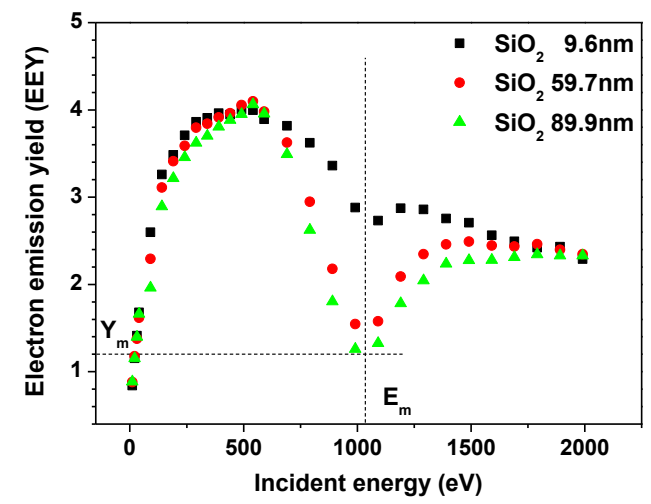

Fig. 2. EEY from very thin silica layers.

Figure 2 represents the EEY from the $\mathrm{SiO}_{2}$ layers in the low energy range up to $2 \mathrm{keV}$. As typical for dielectric materials the EEY is much higher than unity. The maximum yield $Y_{m}=4.0$ is achieved for energy of the PE of $500 \mathrm{eV}$. The obtained value is in accordance with reported in the literature data [7]. For PE of energy $\mathrm{E}_{\mathrm{m}} \approx 1 \mathrm{keV}$ we observe a departure from the general trend of EEY. The obtained dip is heavily dependent on the layer thickness. Such behavior can be related with increased conductivity of the layer, suggesting radiative induced conductivity.

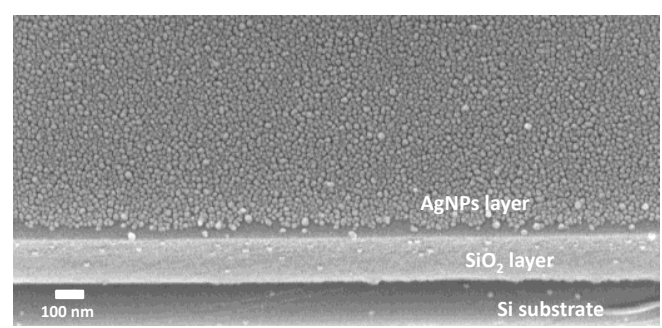

Fig. 3. SEM image (tilted at $30^{\circ}$ ) of the monolayer of AgNPs deposited on thermally grown silica layer.

The obtained monolayer of AgNPs is shown in Fig. 3. After processing of the SEM images taken in plane view we obtained mean size of the AgNPs of $20 \mathrm{~nm}$ and a density of $3.6 \times 10^{11} \mathrm{~cm}^{-2}$. The AgNPs are isolated and the interparticle distance is of about $5 \mathrm{~nm}$.

Figure 4 shows that the EEY from isolated AgNPs deposited on $\mathrm{SiO}_{2}$ thin layer combines properties of metallic silver and the underlying dielectric layer. The maximum yield is reduced to the value of a continuous silver surface and the modulation depth is lowered as the conductivity of the surface is increased through charge transport in the plane.

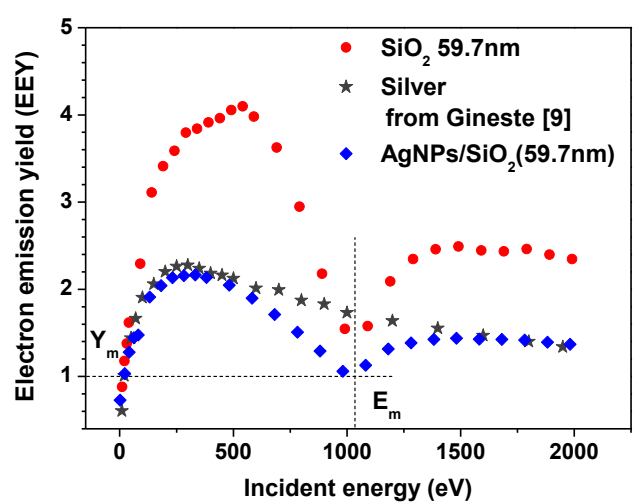

Fig. 4. Comparison of the EEY from $\mathrm{SiO}_{2}\left(\mathrm{~d}_{2}=59.7 \mathrm{~nm}\right)$, silver surface (adapted from [9]) and a structure of monolayer of AgNPs deposited on $\mathrm{SiO}_{2}(59.7 \mathrm{~nm})$ on Si-substrate.

\section{CONCLUSION}

In this contribution we have reported on the EEY from very thin layers. It is found that for dielectric $\mathrm{SiO}_{2}$ layers of thickness less than $100 \mathrm{~nm}$ a departure from the general behaviour occurs for incident electrons with energy of around $1 \mathrm{keV}$. The departure in the electron emission yield heavily depends on the layer thickness. The case of nanostructured layers containing metal nanoparticles shows smooth transition when increasing the layer conductivity.

\section{ACKNOWLEDGMENT}

The authors acknowledge technical assistance from Mr. Benoit Schlegel, LAPLACE laboratory, for sample preparation, support from the UMS Raymond Castaing of the Université de Toulouse and thank Mr. Stéphane Le Blond du Plouy for the SEM observations.

\section{REFERENCES}

[1] B. L. Thiel and M. Toth, "Secondary electron contrast in lowvacuum/environmental scanning electron microscopy of dielectrics," J. Appl. Phys., vol.97, p. 051101, 2005.

[2] Yu. P. Raizer, Gas Discharge Physics. Berlin: Springer, 1991.

[3] N. Balcon, D. Payan, M. Belhaj, T. Tondu, and V. Inguimbert, "Secondary Electron Emission on Space Materials: Evaluation of the Total Secondary Electron Yield from Surface Potential Measurements," IEEE Trans. Plasma Sci., vol. 40(2), pp. 282-290, 2012.

[4] A. Dunaevsky, Y. Raitses, N. J. Fisch, "Secondary electron emission from dielectric materials of a Hall thruster with segmented electrodes," Phys. Plasmas, vol. 10, pp. 2574-2577, 2003.

[5] K. Ohmi, "Beam-photoelectron interactions in positron storage rings," Phys. Rev. Lett., vol. 75, pp. 1526-1529, 1995.

[6] H. Bruining, Physics and applications of secondary electron emission. New York: McGraw-Hill, 1954.

[7] I. A. Glavatskikh, V. S. Kortov and H.-J. Fitting, "Self-consistent electrical charging of insulation layers and metal-insulatorsemiconductor structures," J. Appl. Phys., vol. 89, pp. 440-448, 2001.

[8] K. Makasheva, C. Villeneuve-Faure, C. Bonafos, C. Laurent, A. Pugliara, B. Despax, L. Boudou, and G. Teyssedre, "Dielectric Engineering of Nanostructured Layers to Control the Transport of Injected Charges in Thin Dielectrics," IEEE TNANO, vol. 15, pp. 839-848, 2016.

[9] T. Gineste, M. Belhaj, G. Teyssedre and J. Puech, "Investigation of the electron emission properties of silver: From exposed to ambient atmosphere Ag surface to ion-cleaned Ag surface," Appl. Surf. Sci., vol. 359, pp. 398-404, 2015. 